\title{
Bioactivity-Guided Single-Step Isolation of Stachyspinoside from Sideritis congesta by Centrifugal Partition Chromatography
}

\author{
Julian Osthoff $(\mathbb{D}$, Christophe Carola $(\mathbb{D}$, Andrew Salazar $(\mathbb{D}$, and Joerg von Hagen $(\mathbb{D}$ \\ Merck KGaA, Surface Solutions, Cosmetics Actives R\&D, Darmstadt, Germany \\ Correspondence should be addressed to Julian Osthoff; julian.osthoff@merckgroup.com
}

Received 29 September 2021; Accepted 17 November 2021; Published 9 December 2021

Academic Editor: Eulogio J. Llorent Mart nez

Copyright (C) 2021 Julian Osthoff et al. This is an open access article distributed under the Creative Commons Attribution License, which permits unrestricted use, distribution, and reproduction in any medium, provided the original work is properly cited.

\begin{abstract}
Sideritis congesta is a plant native to Mediterranean countries. Infusions of this plant are used to treat various diseases. The antiinflammatory potential of Sideritis species is widely known. However, the anti-inflammatory potential of an aqueous extract of $S$. congesta has not been investigated yet. In this study, the phytochemical composition and anti-inflammatory potential of different fractions of an aqueous extract from $S$. congesta using bioactivity guided fractionation via centrifugal partition chromatography (CPC) were determined. A CPC single-step isolation of a flavonoid stachyspinoside $\mathbf{1}$ from $S$. congesta is reported. In addition, a CPC fractionation protocol of the crude aqueous extract was developed. Three aqueous fractions (I, II, and III) of $S$. congesta were obtained, and their anti-inflammatory potential was evaluated with respect to their ability to inhibit the activity of COX-2 and NF- $\kappa$ B in vitro. Fraction I showed the highest COX-2 inhibition activity ( $92.3 \%$ inhibition at $0.1 \%)$. Fraction III showed the highest NF- $\kappa \mathrm{B}$ inhibition activity $(99.9 \%$ at $0.1 \%)$ among the CPC produced fractions. The structures of 3 compounds of fraction III could be identified and were validated by HPLC-PDA, HRMS, and NMR spectroscopy. Finally, the phenol, saponin, and flavonoid contents were quantified in the most potent CPC fractions (I and III).
\end{abstract}

\section{Introduction}

Sideritis species belongs to the Lamiaceae family and comprises over 150 species spread in the Western Palearctic zone [1]. Aerial parts of plants from the Sideritis genus are used in the traditional medicines of Mediterranean countries to prepare infusions $[2,3]$. These infusions are utilized for the treatment of cough, blood pressure [4], and obesity [5]. In previous studies, the antioxidant and anti-inflammatory activities of different extracts from several Sideritis species have been reported [6-8]. These activities have been ascribed to the flavonoids, diterpenoids [9], and phenylethanoids isolated from the Sideritis species [10]. Under the genus Sideritis, this study focuses on the plant S. congesta, since among infusions from 7 Sideritis species, the richest infusion in terms of the total phenol and total flavonoid contents belongs to $S$. congesta [11]. However, the anti-inflammatory effects of an aqueous $S$. congesta extract have not been described in the literature yet. A study of the evaluation of an ethanolic S. congesta extract for anti-inflammatory activity showed no significant results [12]. The presence of entkaurane diterpenoids $[9,13]$, flavonoids $[6,14]$, and essential oils $[15,16]$ in aerial parts of $S$. congesta has been described. The presence of kaurenes, an important group of diterpenoids in S. congesta, should be emphasized. These are found in many medicinal plants and have a variety of biological effects, including anti-inflammatory and antioxidant activities [17]. An enrichment and isolation of compounds from an aqueous $S$. congesta extract was developed to provide a better understanding of the origin of the known anti-inflammatory activity of this plant. The anti-inflammatory potential of this plant extract is determined in vitro by evaluating the inhibitory activity on COX-2 (enzymatic assay) and NF- $\kappa$ B in a HEK 293 reporter cell line.

Centrifugal partition chromatography (CPC) is a type of hydrostatic countercurrent chromatography (CCC) that uses two immiscible liquid phases without any solid support [18]. The chromatographic separation principle is based on different partition coefficients $(K)$ of each compound between the stationary and mobile phases. This partition 
coefficient is expressed as the concentration of a target compound in the stationary phase divided by the concentration in the mobile phase [19]. In addition, isolation of a single compound requires a separation factor $\propto>1.5$. The separation factor is expressed as the quotient of two partition coefficients $(K)$ [20]. Using CPC offers various advantages over solid-liquid chromatography processes as CPC allows a fractionation and purification of bioactive compounds from natural products. This includes a higher stationary phase volume [21], which leads to a higher sample load capacity, no irreversible adsorption on the solid phase [21], and therefore maximum sample recovery [22]. Furthermore, CPC consumes less solvent in comparison to solid-liquid chromatography [22] and affords a predictive scale-up from analytical to preparative scale [23]. Particles are tolerated as well, so filtering a sample is not mandatory and a direct separation of crude extracts is possible [24].

$\mathrm{CPC}$ is used to isolate active fractions from the complex aqueous crude extract of $S$. congesta to enrich and identify anti-inflammatory components. In addition, the first preparative isolation of the flavonoid stachyspinoside 1 (Figure 1) via CPC from S. congesta is shown. The aim of the present study was to determine the phytochemical composition and identify anti-inflammatory active ingredients in reduced complexity by fractionation with CPC. Moreover, the most active fractions were enriched in repetitive runs for further characterization of secondary metabolites.

\section{Material and Methods}

2.1. Plant Material and Chemicals. The dried S. congesta plant was obtained from Wortmann AIG (Germany). Solvents used for the extraction, purification, and analytical steps/chromatographic procedures were of HPLC grade, including tert-butyl methyl ether and acetonitrile (Merck KGaA, Germany). Water was obtained by a Millipore Milli$\mathrm{Q}^{\circledR} \quad$ water purification system. Ammonium acetate (Emsure ${ }^{\circledR}$ grade, Merck KGaA) was utilized as additive to the biphasic solvent system in CPC. Caffeine (article no.: 56396-100 mg, Merck KGaA) was purchased as an internal standard for the quantification of natural compounds and the partition coefficient determination.

2.2. Apparatus. The extraction of the $S$. congesta plant was performed on a Thermo Scientific ${ }^{\mathrm{TM}}$ Dionex $^{\mathrm{TM}}$ ASE $^{\mathrm{TM}} 350$ device. A description of the instrument has been mentioned previously [25]. A centrifuge (Thermo Scientific ${ }^{\mathrm{TM}}$ Heraeus $^{\mathrm{TM}}$ Multifuge $^{\mathrm{TM}} \mathrm{X} 3 \mathrm{~F}$ ) was used during the determination of the partition coefficient process. Preparative fractionation was performed on a Gilson ${ }^{\circledR}$ CPC 1000 . The device consists of a 1-liter CPC rotor and a fraction collector (Gilson ${ }^{\circledR}$ PLC 2250 UV-1) with a photodiode array detector. HPLC of the collected fractions was performed on a Thermo Scientific ${ }^{\mathrm{TM}}$ UltiMate $^{\mathrm{TM}} 3000$ UHPLC module (Chromeleon 7.2 software) connected to a photodiode array detector (PDA) and a charged aerosol detector (CAD) using a Chromolith ${ }^{\circledR} \mathrm{HR}$
RP-18e column $(100 \mathrm{~mm} \times 4.6 \mathrm{~mm}$ id; Merck KGaA, Darmstadt). Determination of total phenolic and saponin content was performed with an Agilent Cary $60 \mathrm{UV}$-Vis spectrophotometer. All experiments related to the biological activity were evaluated on a Spark ${ }^{\circledR} 20 \mathrm{M}$ microplate reader (Tecan Group Ltd.). HRMS analyses were performed with a Thermo Scientific ${ }^{\mathrm{TM}}$ Q Exactive $\mathrm{T}^{\mathrm{TM}}$ Plus mass spectrometer coupled with an HESI source. NMR analyses were performed with Bruker Avance III instrument $(700 \mathrm{MHz})$.

2.3. Plant Extract Preparation and Treatment. The plant material ( $60 \mathrm{~g}$ of leaves and stems) was grounded and mixed $1: 1$ with diatomaceous earth and was extracted in an $\mathrm{ASE}^{\mathrm{TM}}$ 350 device with water for 6 minutes at $90^{\circ} \mathrm{C}$ (three cycles) and 100 bar in a $100 \mathrm{~mL}$ SST (stainless steel) extraction cell. After concentration under vacuum, the concentrate was cooled at $5-10^{\circ} \mathrm{C}$. The concentrate was precipitated and filtrated, and the residue was dried under vacuum to provide $2.5 \mathrm{~g}$ crude extract. The yield of extraction was calculated as follows.

$$
\text { Yield of extraction }=\frac{\text { mass of dried extract }}{\text { mass of plant }} \times 100 \% .
$$

2.4. HPLC Analysis of Crude Extracts. Prior to screening in all biological assays, the crude extract and all CPC fractions were analyzed by HPLC. The analysis was performed using a Thermo Scientific ${ }^{\mathrm{TM}}$ UltiMate $^{\mathrm{TM}} 3000$ HPLC system equipped with a Chromolith ${ }^{\circledR}$ HR RP18e column $(100 \mathrm{~mm} \times 4.6 \mathrm{~mm}$, $5 \mu \mathrm{m}$, Merck KGaA, Germany). The mobile-phase flowrate was set to $1 \mathrm{~mL} / \mathrm{min}$. A linear gradient of acetonitrile (B) and water (A) was used. The gradient extended from 0 to $44 \mathrm{~min}$ and consisted of $5-80 \%$ B (for details, see Appendix). The samples were monitored at $260 \mathrm{~nm}$. A quantification of compounds was performed with a Corona ${ }^{\mathrm{TM}} \mathrm{Veo}^{\mathrm{TM}}$ RS CAD detector system. Therefore, an inverse gradient was used in addition to the normal gradient at a flow rate of $1 \mathrm{~mL} / \mathrm{min}$. Caffeine was used as internal standard.

2.5. Biphasic Solvent System and Partition Coefficient (K Value) Determination for Stachyspinoside. A biphasic solvent system from the terAcWat solvent family was prepared and equilibrated. $2 \mathrm{~mL}$ of the lower phase (water and acetonitrile) and $2 \mathrm{~mL}$ of the upper phase (tert-butyl methyl ether) were transferred to a test tube. The crude extract $(2 \mathrm{mg})$ was added to this biphasic phase. The test tube was shaken for 30 minutes, mixed in a centrifuge for 3 minutes at $1500 \mathrm{rpm}$, and allowed to settle for $5 \mathrm{~min}$. The organic phase $(0.7 \mathrm{~mL})$ was taken, evaporated to dryness, and dissolved in the same volume $(0.7 \mathrm{~mL})$ of HPLC $\left(\mathrm{H}_{2} \mathrm{O} / \mathrm{ACN} 8: 2\right)$ eluent. Afterwards, the upper and lower phases were analyzed by HPLC ( $20 \mu \mathrm{L}$ injection volume) at $260 \mathrm{~nm}$. The $K$ value was expressed as the peak area of compounds in the upper phase divided by that in the lower phase (2). The separation factor $\propto$ was calculated as the quotient between two $K$ values (3). 


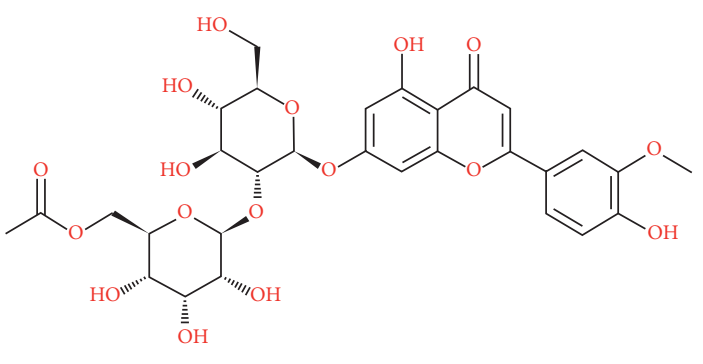

Stachyspinoside 1

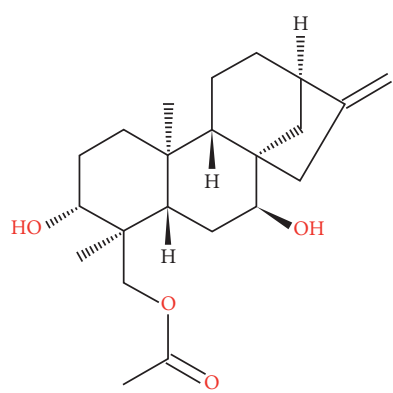

Linearol 2

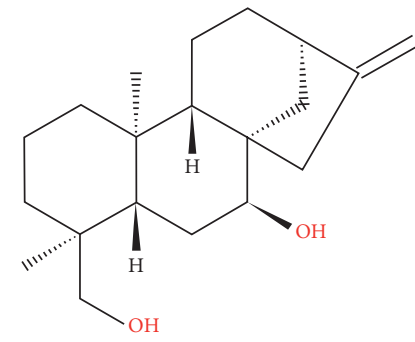

Epicandicandiol 3

Figure 1: Chemical structures of the isolated compounds in S. congesta. (a) Stachyspinoside 1. (b) Linerol 2. (c) Epicandicandiol 3.

$$
\begin{aligned}
& K=\frac{c(\text { peak area upper phase })}{c \text { (peak area lower phase })}, \\
& \propto=\frac{K_{1}}{K_{2}}, \quad K_{1}>K_{2} .
\end{aligned}
$$

2.6. Centrifugal Partition Chromatography (CPC) Separation of the Crude Extract. CPC separations were performed using a two-phase solvent system composed of 3 solvents: tertbutyl methyl ether, acetonitrile, and water (terAcWat). The isolation of stachyspinoside $\mathbf{1}$ was performed using the solvent system terAcWat +1.5 (3.5:6.5:10, v/v). To increase the separation factor $\propto$, ammonium acetate $(0.1 \%)$ was added to the solvent system. The fractionation of the crude extract was carried out with the solvent system terAcWat +1 $(4: 6: 10, \mathrm{v} / \mathrm{v})$ to further enrich secondary metabolites. First, the column was filled with the stationary phase; then the apparatus was rotated at $1500 \mathrm{rpm}$ and the CPC column was equilibrated with the mobile phase at a flow rate of $30 \mathrm{~mL} /$ $\mathrm{min}$ or $50 \mathrm{~mL} / \mathrm{min}$. After having reached the hydrodynamic equilibrium, a sample solution $(50 \mathrm{~mL})$ was injected into the column. The separation was performed at a flow rate of $30 \mathrm{~mL} / \mathrm{min}$ or of $50 \mathrm{~mL} / \mathrm{min}$ and monitored with a PDA detector at $260 \mathrm{~nm}$. The fractions were collected in $25 \mathrm{~mL}$ test tubes and evaporated under vacuum at $60^{\circ} \mathrm{C}$. A fractionation of the extract was performed once in the ascending mode and once in the descending mode. The obtained fractions were dissolved in an acetonitrile/water mixture for HPLC analysis.

2.7. Cell Viability. The crude extract of S. congesta and its fractions were evaluated for their cytotoxicity on HEK 293 cells. The evaluation of the cell viability was carried out by the determination of adenosine triphosphate (ATP) content by firefly luciferase. This method enabled an assessment of the in vitro cytotoxicity. The ATPlite 1step luminescence assay was performed as recommended in the kit manual (Perkin Elmer). Cell media was used as a positive control. This signal was set to $100 \%$ viability. Tween 80 was selected as negative control. This signal was set to $100 \%$ cytotoxicity. All samples were tested at concentrations between 0.1 and $0.0001 \%$ and normalized between 0 and $100 \%$. The concentration causing $50 \%$ toxicity $\left(\mathrm{TC}_{50}\right)$ was calculated assuming that the dose response curve will a standard slope, equal to a hill slope of -1.0 . The concentration causing $20 \%$ toxicity $\left(\mathrm{TC}_{20}\right)$ serves as a reference for the maximum concentration of the natural product fractions used.

2.8. Enzymatic COX-2 Inhibition. Inhibition of enzymatic COX-2 was quantified using the fluorometric COX-2 inhibitor screening kit (BioVision, USA). The assay was performed as recommended in the kit manual (BioVision, 2018a). Measurement of the fluorescence signal (Ex/ $\mathrm{Em}=535 / 587 \mathrm{~nm}$ ) was recorded kinetically at $25^{\circ} \mathrm{C}$ for $10 \mathrm{~min}$. Afterwards, two appropriate points $\left(T_{1}\right.$ and $\left.T_{2}\right)$ in the linear range of the plot were chosen and the corresponding fluorescence values $\left(\mathrm{RFU}_{1}\right.$ and $\left.\mathrm{RFU}_{2}\right)$ were obtained. Each natural product sample was tested at a concentration of $0.1 \%$. All samples were analyzed 6-fold. Celecoxib $(0.5 \mu \mathrm{M})$ was used as a positive control. The calculation of the slope for all samples (S), including enzyme control (EC), was performed by dividing the $\triangle \mathrm{RFU}$ $\left(\mathrm{RFU}_{2}-\mathrm{RFU}_{1}\right)$ values by the time $\Delta T\left(T_{2}-T_{1}\right)$. Percentage of relative inhibition was calculated as follows:

$$
\% \text { relative inhibition }=\frac{\text { slope of } \mathrm{EC}-\text { slope of } \mathrm{S}}{\text { slope of } \mathrm{EC}} \times 100 \% \text {. }
$$

2.9. Cellular $N F-\kappa B$ Inhibition. Inhibition of $N F-\kappa B$ was quantified using GloResponse ${ }^{\mathrm{TM}}$ NF- $\kappa \mathrm{B}-\mathrm{RE}-\mathrm{luc} 2 \mathrm{P}$ HEK 293 cell line. Cells were cultivated in a suitable culture medium (DMEM) in an incubator at $37^{\circ} \mathrm{C}$ with $5 \% \mathrm{CO}_{2}$. The assay was performed as recommended in the kit manual (Promega). A TNF alpha solution in assay medium $(0.1 \mu \mathrm{g} /$ $\mathrm{mL}$ TNF alpha) was used to induce NF- $\kappa \mathrm{B}$ activity. A positive control $10 \mu \mathrm{M}$ dexamethasone in assay medium was selected. Furthermore, an unstimulated control composited of cells in assay medium and a cell-free control composited of assay medium were measured to subtract background luminescence signal (see the equation below). All samples were tested at a concentration of $0.1 \%$. Each sample was analyzed as replicates $(n=6)$. Luminescence signal was measured to compare the biological activity of the separated natural product fractions as follows: 
induction $=\frac{(\text { average stimulated wells }- \text { average cellfree control wells })}{(\text { average unstimulated wells }- \text { average cellfree control wells })}$

2.10. Quantification of Total Phenolic Content. The total phenolic content was determined using the Folin-Ciocalteu method [26]. Aqueous stock solutions $(1 \mathrm{mg} / \mathrm{mL})$ were prepared for each extract sample. The sample solution $(1 \mathrm{~mL})$ was transferred into a $20 \mathrm{~mL}$ volumetric flask. $0.2 \mathrm{~N}$ Folin-Ciocalteu reagent $(10 \mathrm{~mL})$ and sodium carbonate solution $(7.5 \%, 8 \mathrm{~mL})$ were added. Finally, the volumetric flask is filled up with demineralized water. After $2 \mathrm{~h}$ of incubation at room temperature, the sample absorbance was measured at $765 \mathrm{~nm}$. The blank is prepared using $1 \mathrm{~mL}$ of water by the same procedure as described above. Reference substance was gallic acid (five-point calibration, 25-150 $\mathrm{g}$ / $\mathrm{mL}$ ). The total phenolic content was expressed as milligrams gallic acid equivalents (mg GAE/g extract) (curve equation: $\left.Y=0.005573 x-0.018238 ; R^{2}=0.998\right)$.

2.11. Quantification of Total Saponin Content. Total saponin content was determined according to an adapted method of Oludemi et al. [27]. Aqueous stock solutions $(1 \mathrm{mg} / \mathrm{mL})$ were prepared for each extract sample. A sample solution $(200 \mu \mathrm{L})$ was transferred into a $10 \mathrm{~mL}$ test tube and evaporated under reduced vacuum at $60^{\circ} \mathrm{C}$. A vanillin-glacial acetic acid solution $(5 \% \mathrm{w} / \mathrm{v}, 300 \mu \mathrm{L})$ and a perchloric acid solution $(70 \%$, $1 \mathrm{~mL}$ ) were added to the residue. The mixture was shaken vigorously for 10 seconds and incubated for $45 \mathrm{~min}$ at $60^{\circ} \mathrm{C}$ in a closed test tube. Then, the tubes were cooled in an ice bath for 10 minutes. Glacial acetic acid $(4.5 \mathrm{~mL})$ was added to this mixture and was shaken again for 10 seconds. The sample absorption was measured at $540 \mathrm{~nm}$ in a $1 \mathrm{~mL} \mathrm{cu-}$ vette. The extracts were measured against a blank. This blank contained the extract solution $(200 \mu \mathrm{L})$ prepared using the procedure described above, but glacial acetic acid was added instead of the vanillin-glacial acetic acid solution. Reference was oleanolic acid (six-point calibration, 12.5-400 $\mu \mathrm{g} / \mathrm{mL}$ ). The total saponin content was expressed as milligrams oleanolic acid equivalents (mg OAE/g extract) (curve equation: $\left.Y=0.001722 x-0.005892 ; R^{2}=0.999\right)$.

2.12. Quantification of Total Flavonoid Content. The total flavonoid content was determined using a modified method $\left(\mathrm{AlCl}_{3}\right)$ described by Chang et al. [28]. Aqueous stock solutions $(1 \mathrm{mg} / \mathrm{mL})$ were prepared for each extract sample. The sample solution $(1 \mathrm{~mL})$ was transferred into a $20 \mathrm{~mL}$ volumetric flask and mixed with ethanol $(2.8 \mathrm{~mL})$, aluminium chloride solution $(10 \%, 0.16 \mathrm{~mL})$, and potassium acetate $(1 \mathrm{M}, 0.16 \mathrm{~mL})$. Finally, the volumetric flask is filled up with demineralized water. After $30 \mathrm{~min}$ of incubation at room temperature, the sample absorbance was measured at $380 \mathrm{~nm}$. The blank is prepared using water $(1 \mathrm{~mL})$ with the same procedure described above. Stachyspinoside 1 (sixpoint calibration, $10-200 \mu \mathrm{g} / \mathrm{mL}$ ) was used as a reference standard as it is a known flavonoid in S. congesta. The total flavonoid content was expressed as milligrams of stachyspinoside equivalents ( $\mathrm{mg} \mathrm{SE} / \mathrm{g}$ extract) (curve equation: $\left.Y=0.001609 x-0.010299 ; R^{2}=0.994\right)$.

2.13. Quantification and Structure Identification of Secondary Metabolites. The analysis of fraction III was performed using a Thermo Scientific ${ }^{\mathrm{TM}}$ UltiMate $^{\mathrm{TM}} 3000$ HPLC system equipped with a Chromolith ${ }^{\circledR}$ HR RP18e column (100 mm $\times 4.6 \mathrm{~mm}, 5 \mu \mathrm{m}$, Merck KGaA, Germany). The mobile phase flowrate was set to $0.9 \mathrm{~mL} / \mathrm{min}$. A linear gradient of acetonitrile (B) and water (A) was used. The gradient extended from 0 to $66 \mathrm{~min}$ and consisted of $5-80 \%$ $\mathrm{B}$ (for details, see Appendix). A Corona ${ }^{\mathrm{TM}} \mathrm{Veo}^{\mathrm{TM}} \mathrm{RS} \mathrm{CAD}$ detector system was applied for the quantification. Therefore, an inverse gradient was used in addition to the normal gradient at a flow rate of $0.9 \mathrm{~mL} / \mathrm{min}$. The quantification was performed with caffeine as internal standard (calibration curve equation: $Y=1.1746 x-0.0623 ; R^{2}=0.999$ ).

All HESI-MS experiments were performed on a Thermo Scientific ${ }^{\mathrm{TM}}$ Vanquish HPLC system equipped with a Thermo Scientific $^{\mathrm{TM}}$ Q Exactive Plus (MS) in positive ionization mode. ${ }^{1} \mathrm{H}$ - and ${ }^{13} \mathrm{C}-\mathrm{NMR}$ spectra were recorded with a Bruker Avance III instrument $(700 \mathrm{MHz}$, probehead: $\mathrm{CP}$ TCI, software: TopSpin version 3.1 pl6). Tetramethylsilane was used as internal standard. Samples were dissolved in DMSO- $\mathrm{d}_{6}$. The raw data can be found in Appendix.

2.14. Statistical Analysis. The data obtained in in vitro experiments were reported as the mean \pm standard deviation (SD), and the parameter comparisons between groups were performed by one-way variance analyses (ANOVA). Tukey's test followed the ANOVA comparison of the COX-2 results, with every mean being compared to every other mean value. Dunnett's post hoc analysis followed the ANOVA comparison of the NF- $\kappa \mathrm{B}$ results, with every mean value being compared with the mean of the control (TNF alpha). The data obtained in the group determination experiments were reported as the mean \pm standard deviation (SD). All analyses were conducted using the Prism 7.5 software (GraphPad Software).

\section{Results and Discussion}

3.1. Plant Extraction and HPLC Analysis of Crude Extract. An overview of the performed process on $S$. congesta is described in Figure 2. The aqueous extraction of $60 \mathrm{~g}$ plant material provided $2.5 \mathrm{~g}$ of a brownish $S$. congesta crude extract. The calculated yield following (1) is $4.2 \%$. An instrumental analysis (HPLC) of the obtained extract is shown in Figure 3. The use of an internal standard resulted in the determination of the mass fraction of stachyspinoside $\mathbf{1}$ (61.1\%). The presence of the flavonoid stachyspinoside $\mathbf{1}$ in S. congesta was first reported in 2020 [29]. In addition, the HPLC-CAD chromatogram (Figure 3) showed that the extract quantitatively contained polar compounds (retention 


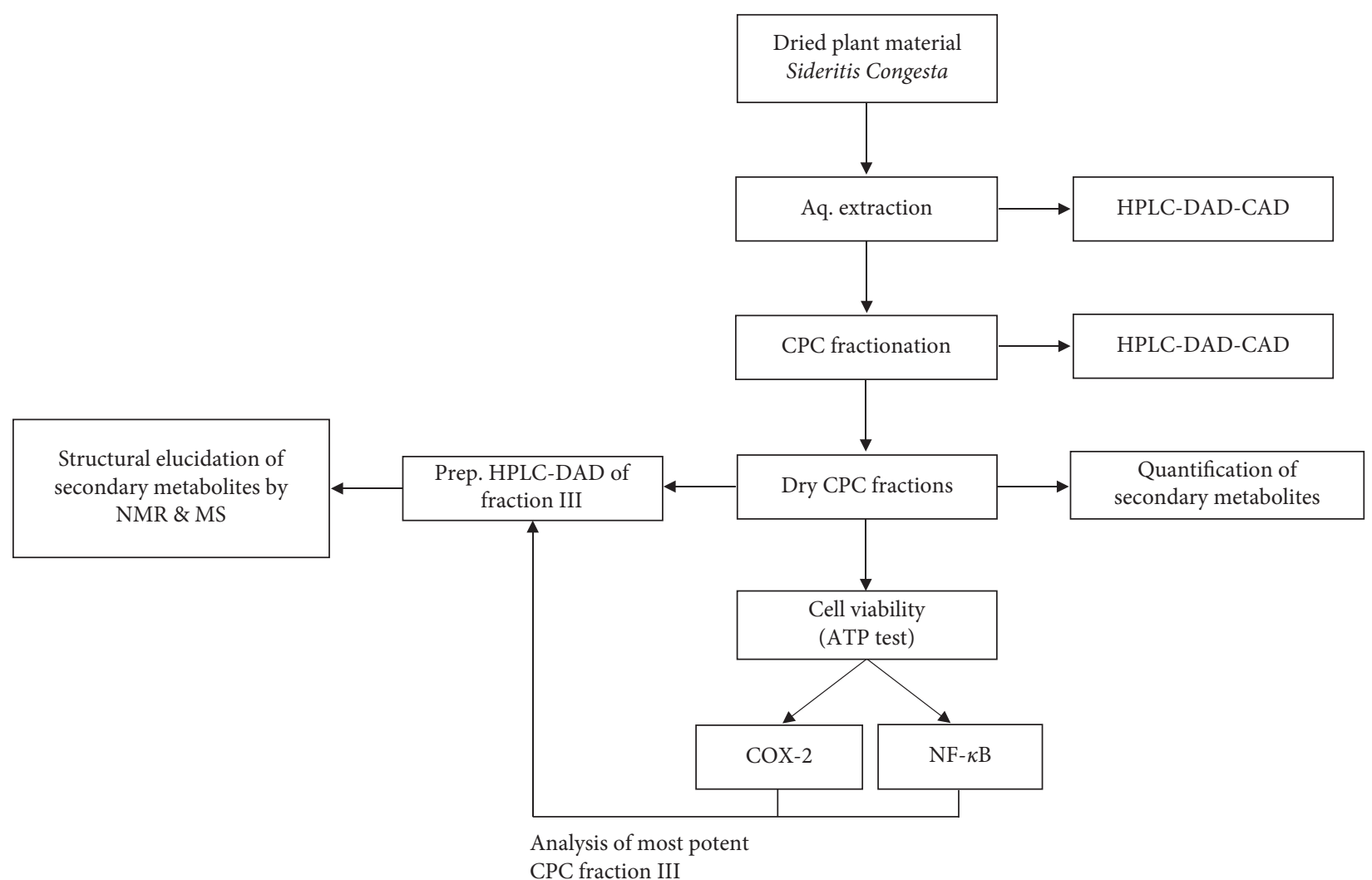

FIGURE 2: Schematic diagram of the performed process in this study.

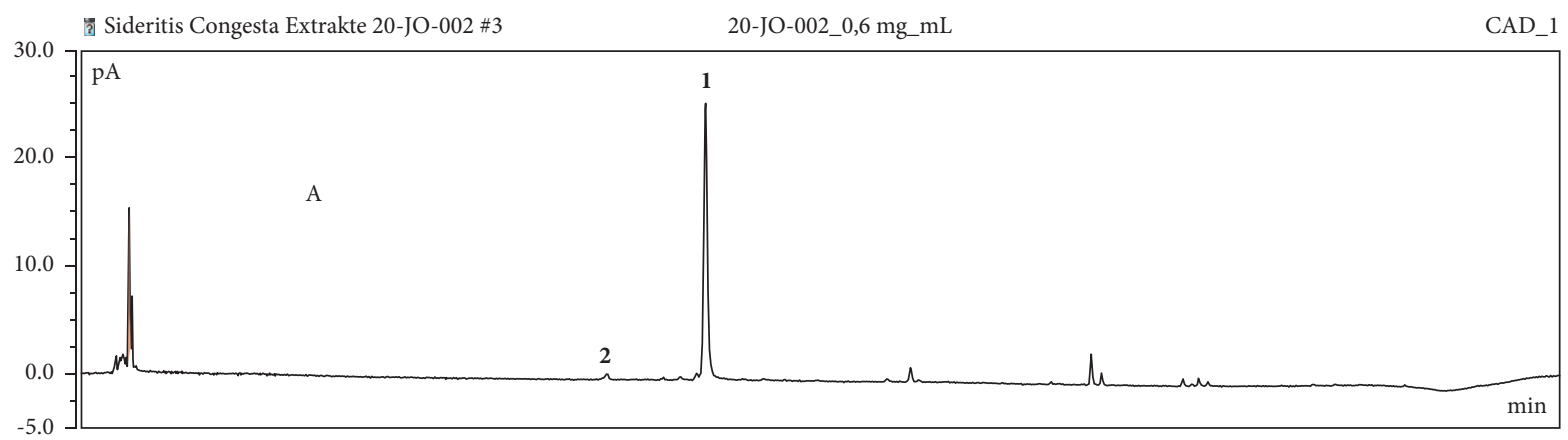

(a)

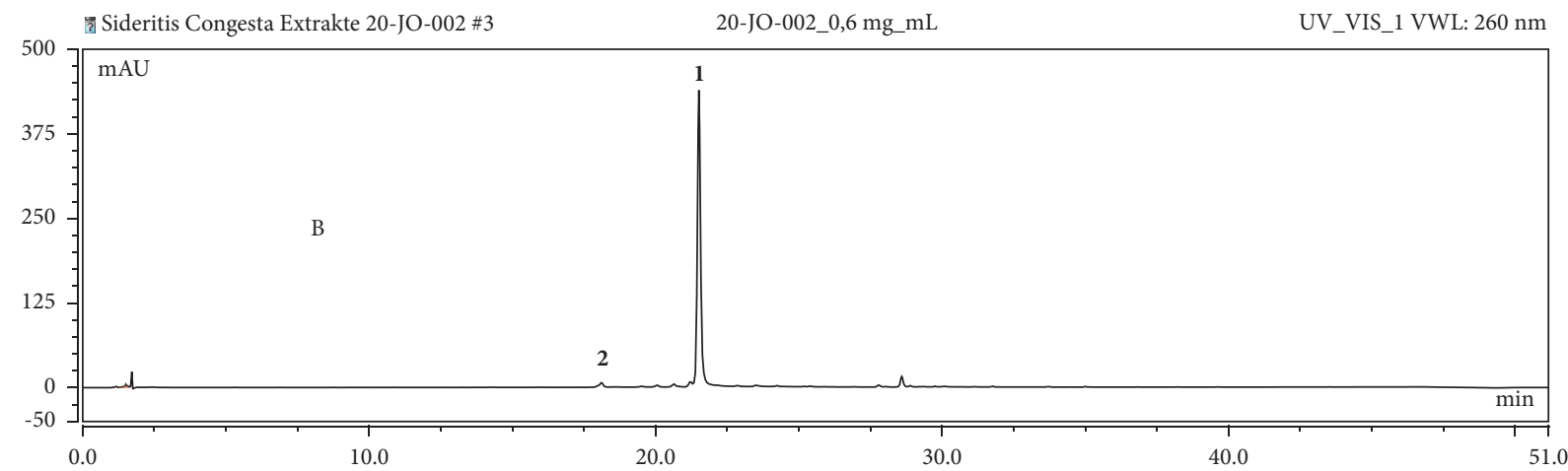

(b)

FIGURE 3: HPLC chromatograms of the aqueous crude extracts obtained from S. congesta with a charged aerosol detector (CAD) (a) and PDA detector at $260 \mathrm{~nm}$ (b). The peak at $21.6 \mathrm{~min}$ corresponds to stachyspinoside (1), and the peak at $18.1 \mathrm{~min}$ (2) corresponds to the highest closest peak to stachyspinoside and was considered for the calculation of the separation factor $\propto$. 
time around $2 \mathrm{~min}$ ) and a lower intensity of nonpolar compounds (retention time between 28 and $40 \mathrm{~min}$ ).

3.2. Selection of Solvent System for CPC. Efficient separation of target compounds by CPC requires the choice of an appropriate two-phase solvent system. The selected system should incorporate the following aspects: an ideal partition coefficient $(0.2<K<5)$, a sufficient separation factor $(\propto>1.5)$, a short settling time of the solvent system $(<25 \mathrm{~s})$ [20], and a satisfactory stationary phase retention $(>60 \%)[30]$.

The partition coefficients and separation factors for different solvent systems are summarized in Table 1 . All partition coefficients are in the required range $(0.2<K<5)$ [20]. It is shown that the addition of ammonium acetate $(0.1 \%)$ increased the selectivity of the solvent system, which leads to a higher separation factor $(\propto)$ [31]. The settling time of terAcWat +1.5_0.1\%AA is $10 \mathrm{~s}$.

3.3. CPC Separation of Stachyspinoside from the Crude Extract. Based on the results of Table 1, terAcWat $+1.5 \_0.1 \%$ AA was selected for the separation of stachyspinoside 1. Initially, the separation process was optimized in the ascending mode as initial experiments showed a higher peak resolution $R_{\mathrm{S}}$ (2.18-fold), separation factor (1.2-fold), and purity (1.1-fold) with a similar stationary retention phase compared to the descending mode. The operating parameters and fluid dynamics have been optimized for the separation. Therefore, the separation is carried out at a rotor speed of $1500 \mathrm{rpm}$ and a flow rate of $50 \mathrm{~mL} / \mathrm{min}$. After optimization, stachyspinoside $\mathbf{1}$ is obtained in a single step during 32.5 minutes with a purity $>95 \%$, a peak resolution $R_{S}$ of 2.0 , and a stationary phase retention of $55 \%$ (Figure 4 ). This study is the first to report the isolation of stachyspinoside 1 using CPC.

The structural identification was achieved with ${ }^{1} \mathrm{H}$-, ${ }^{13} \mathrm{C}-\mathrm{NMR}$ and HRMS (see Appendix).

3.4. CPC Fractionation of the Crude Extract. Besides the compound stachyspinoside $\mathbf{1}$, other secondary metabolites might be responsible for the anti-inflammatory activity. Therefore, 3 fractions were obtained from the crude extract. Using the solvent system terAcWat +1 in the descending mode led to the enrichment of fractions I and II within 26 min (Figure 5(a)). Performing a separation of the crude extract with the same solvent system in the ascending mode led to the enrichment of fraction III within $15 \mathrm{~min}$ (Figure 5(b)).

After the optimization of CPC conditions, the obtained fractions I-III, the stachyspinoside fraction, and the crude extract were tested in vitro for their anti-inflammatory activity. The secondary metabolites of the most potent fractions were further characterized.

3.5. Cell Viability and Anti-Inflammatory Activity. The cytotoxicity of the $S$. congesta crude extract, the stachyspinoside fraction, and fractions I-III on HEK 293 cells was evaluated (Table 2). Based on these results, all experiments
Table 1: Partition coefficients $(K)$ and separation factor $(\propto)$ of stachyspinoside $\mathbf{1}$ in various solvent systems.

\begin{tabular}{|c|c|c|c|}
\hline \multirow[b]{2}{*}{ Solvent system } & \multicolumn{2}{|c|}{ Partition coefficient $(K)$} & \multirow{2}{*}{$\begin{array}{l}\text { Separation } \\
\text { factor } \\
(\propto)^{* * *}\end{array}$} \\
\hline & $\begin{array}{c}\text { Stachyspinoside } \\
\left(K_{1}\right)\end{array}$ & $\begin{array}{l}\text { Peak 2 } \\
\left(K_{2}\right)^{* *}\end{array}$ & \\
\hline terAcWat +1 & 0.88 & 0.71 & 1.2 \\
\hline terAcWat +1.5 & 0.58 & 0.44 & 1.3 \\
\hline $\begin{array}{l}\text { terAcWat } \\
+1.5 \_0.1 \% \mathrm{AA}^{*}\end{array}$ & 0.50 & 0.23 & 2.2 \\
\hline
\end{tabular}

The results are determined in accordance with chapter 2.5 and correspond to the descending mode. ${ }^{*} \mathrm{AA}=$ ammonium acetate. ${ }^{* *}$ Peak 2 corresponds to the highest closest peak to stachyspinoside (retention time $18.1 \mathrm{~min}) .{ }^{* * *} \propto=\mathrm{K}_{1} / \mathrm{K}_{2}, K_{1}>\mathrm{K}_{2}$.

were carried out at a concentration of $0.1 \%$. In addition, fraction II was measured at a concentration of $0.02 \%$ (corresponding to its $\mathrm{TC}_{20}$ ) in the NF- $\kappa \mathrm{B}$ assay, to investigate the influence of the cytotoxicity at $0.1 \%$. The results of the anti-inflammatory potential of the CPC fractions and of the crude extract are compared (see Figure 6). Results of the inhibition of COX-2 indicated that fraction I (92.3\%) and the crude extract (90.2\%) possessed the highest inhibitory activity. Fractions II and III showed a comparable relative inhibition (53.5\% vs. $52.5 \%$ ), while the isolated compound stachyspinoside 1 showed the lowest relative inhibitory potential (45.4\%) (see Figure 6(a)). The positive control Celecoxib had an inhibitory potential of $55.2 \%$ and validated this experiment.

In addition, the anti-inflammatory potential, measured via the inhibition of NF- $\kappa$ B translocation into the nucleus in HEK 293 cells, is illustrated in Figure 6(b). Fraction III (99.9\%) and S. congesta crude extract (44.8\%) significantly inhibited NF- $\kappa \mathrm{B}$ transnucleation compared to the TNF alpha control. Fraction II at a test concentration of $0.02 \%$ showed a significant proinflammatory signal (9.9\%). All other fractions do not differ significantly (ns) from the control. Dexamethasone $(10 \mu \mathrm{M})$ was used as a positive control to validate the experiment.

In conclusion, the crude extract of $S$. congesta significantly inhibited the COX-2 activity and NF- $\kappa \mathrm{B}$ transnucleation, while fraction I and fraction III showed a significant anti-inflammatory activity in only one of the two assays, COX- 2 and NF- $\kappa \mathrm{B}$, respectively. As described previously, $61.1 \%$ of the crude extract contains stachyspinoside 1. In comparison to all other fractions, stachyspinoside $\mathbf{1}$ showed the lowest anti-inflammatory activity on COX-2 and NF- $\kappa \mathrm{B}$. This led to the conclusion that anti-inflammatory potential is mainly attributed to the composition of the remaining $29.9 \%$ of the extract. Therefore, fraction I with the most potent inhibitory activity in the COX-2 assay and fraction III with the most potent inhibitory activity in the NF- $\kappa \mathrm{B}$ assay were further investigated to identify their secondary metabolites composition.

3.6. Quantification of Secondary Metabolites. The phytochemical studies of this $S$. congesta extract revealed the presence of saponins, phenols, and flavonoids. The content of the secondary metabolites in the most potent anti- 


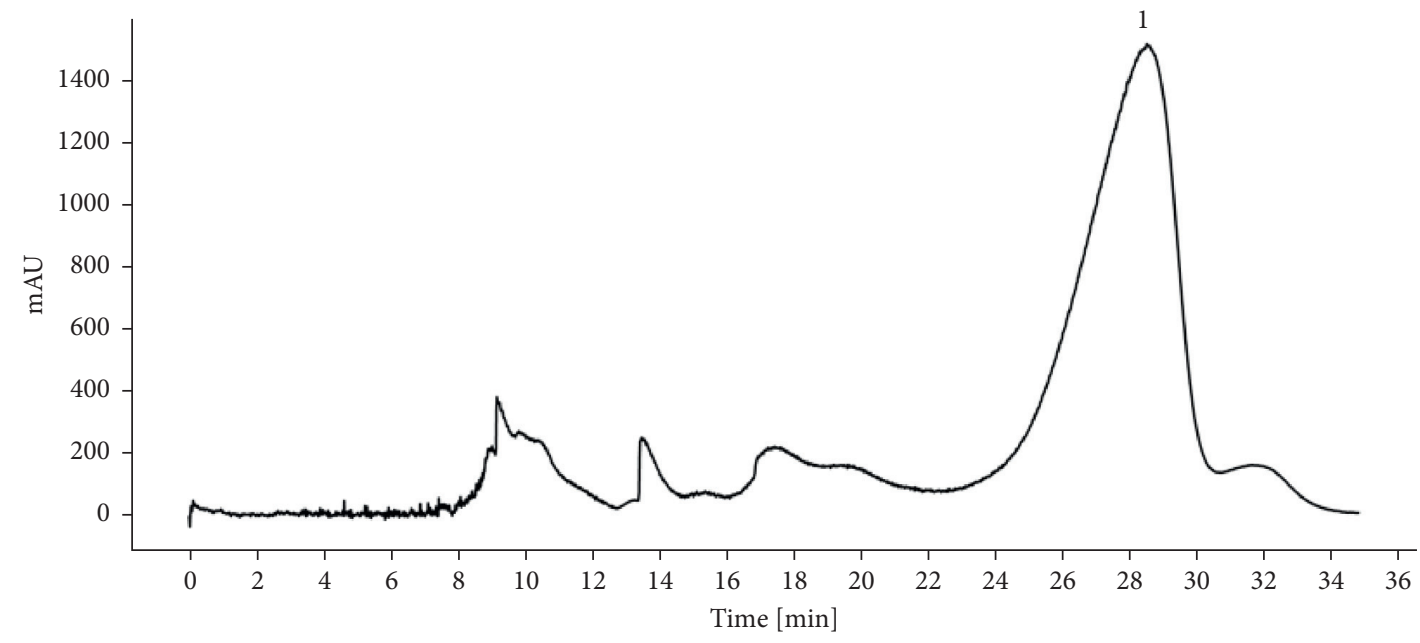

Channel

$-260 \mathrm{~nm}$

Figure 4: CPC separation of stachyspinoside 1 (peak at 28.5 minutes) performed in the ascending mode (detection at $260 \mathrm{~nm}$ ). Solvent system: terAcWat +1.5_0.1\%AA; sample concentration $6 \mathrm{mg} / \mathrm{mL}$; detection wavelength $260 \mathrm{~nm}$; flow rate: $50 \mathrm{~mL} / \mathrm{min}$; rotor speed: $1500 \mathrm{rpm}$; and retention of stationary phase: $55.1 \%$.

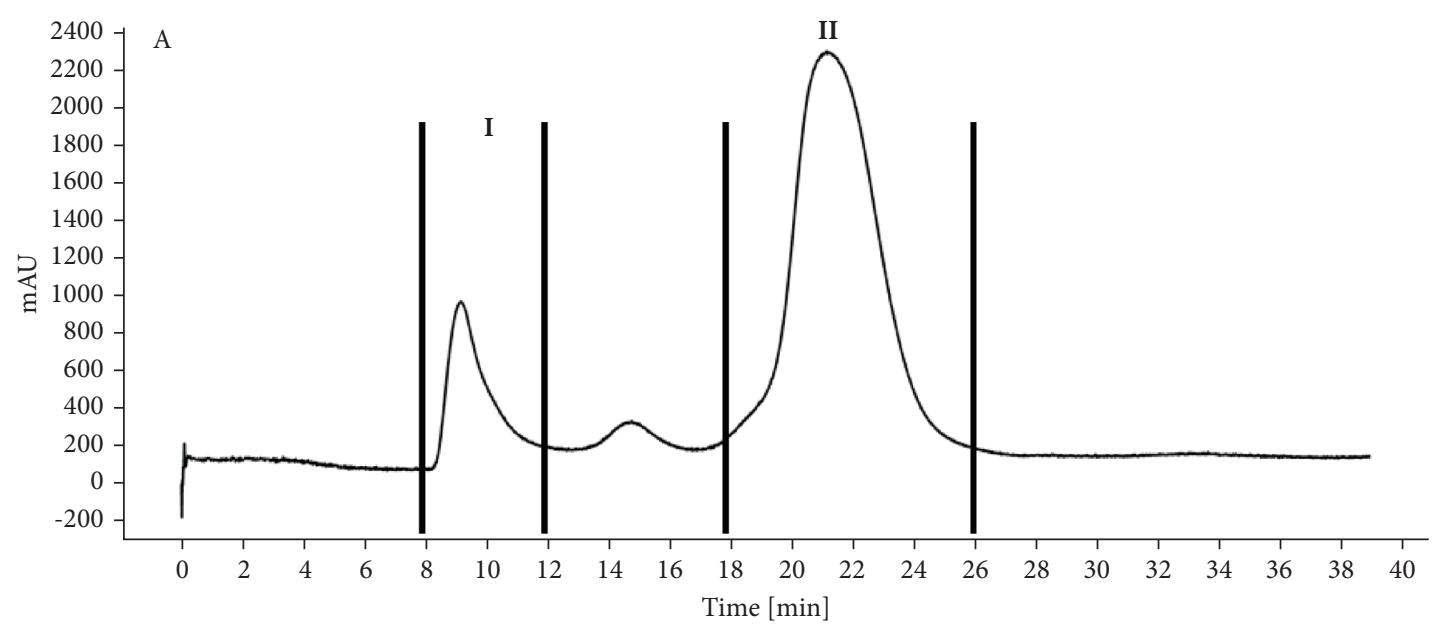

Channel

$-260 \mathrm{~nm}$

(a)

Figure 5: Continued. 


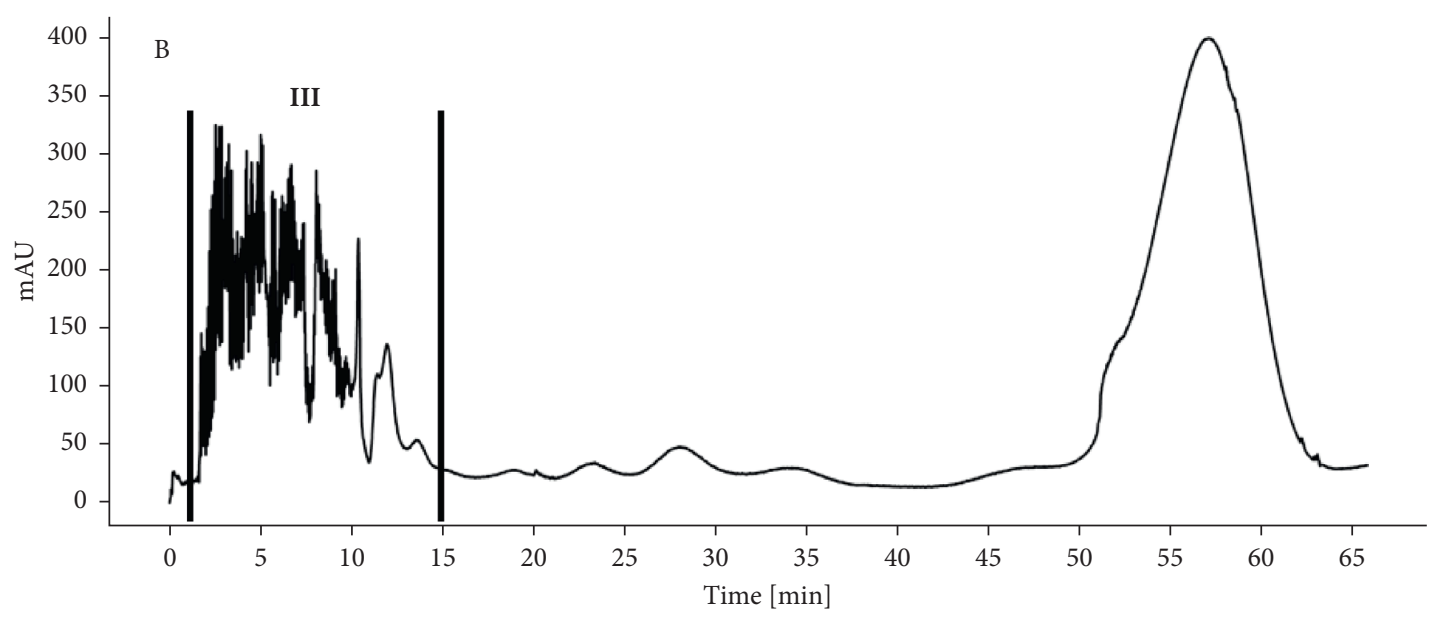

Channel

$-260 \mathrm{~nm}$

(b)

FIgURE 5: (a) Chromatogram of CPC fractionation of the aqueous extract from S. congesta in descending mode. Solvent system: terAcWat +1 ; sample concentration $2 \mathrm{mg} / \mathrm{mL}$; detection wavelength $260 \mathrm{~nm}$; flow rate: $30 \mathrm{~mL} / \mathrm{min}$; rotor speed: $1500 \mathrm{rpm}$; retention of stationary phase: $62.5 \%$; retention time of fraction I ( $8-12 \mathrm{~min}$ ); and retention time of fraction II (18-26 min). (b) Chromatogram of CPC fractionation of the aqueous extract from $S$. congesta in ascending mode. Solvent system: terAcWat +1 ; sample concentration $2 \mathrm{mg} / \mathrm{mL}$; detection wavelength $260 \mathrm{~nm}$; flow rate: $30 \mathrm{~mL} / \mathrm{min}$; rotor speed: $1500 \mathrm{rpm}$; retention of stationary phase: $70.5 \%$; and retention time of fraction III (1.5-15 $\mathrm{min})$.

TABLE 2: Cytotoxicity of $S$. congesta crude extract and CPC fractions on HEK 293 cells.

\begin{tabular}{lc}
\hline Sample & Cytotoxicity $\mathrm{TC}_{20}(\%)$ \\
\hline S. congesta crude extract & 0.11 \\
Stachyspinoside fraction & 1.11 \\
Fraction I & 0.13 \\
Fraction II & 0.02 \\
Fraction III & 0.11 \\
\hline
\end{tabular}

The results are determined within the software Prism 7. HEK 293 cell culture conditions: $5 \% \mathrm{CO}_{2} / 37^{\circ} \mathrm{C}$ humid atmosphere/DMEM cell culture medium.

inflammatory fractions and in the crude extract of S. congesta is presented in Table 3 . The highest amount of phenols was found in the crude extract $(145.0 \pm 0.20 \mathrm{mg}$ GAE/g extract), followed by fraction I ( $102.3 \pm 0.15 \mathrm{mg} \mathrm{GAE} /$ g extract) and fraction III ( $46.4 \pm 0.08 \mathrm{mg} \mathrm{GAE} / \mathrm{g}$ extract). Saponin content was enriched through the CPC purification process. Fraction III showed the highest amount of saponins $(251.7 \pm 0.95 \mathrm{mg} \mathrm{OAE} / \mathrm{g}$ extract), followed by the crude extract $(55.5 \pm 0.87 \mathrm{mg} \mathrm{OAE} / \mathrm{g}$ extract) and fraction I $(39.6 \pm 1.78 \mathrm{mg} \mathrm{OAE} / \mathrm{g}$ extract). Compared to fraction I $(108.5 \pm 0.19 \mathrm{mg} \mathrm{SE} / \mathrm{g}$ extract), a higher flavonoid content was found in the crude extract (158.2 $\pm 1.07 \mathrm{mg} \mathrm{SE} / \mathrm{g}$ extract) and fraction III (152.2 $\pm 0.18 \mathrm{mg} \mathrm{SE} / \mathrm{g}$ extract). These results indicate that phenolic compounds are more concentrated in the polar fraction I after the CPC process while saponins are enriched in the most nonpolar fraction III. The content of flavonoids is distributed between the 3 different CPC fractions. The total flavonoid content should be carefully interpreted. As described above, $61.1 \%$ stachyspinoside 1 was quantified in the crude extract using a HPLC-CAD method with an internal standard. The determined total flavonoid content of the crude extract is significantly lower $(15.8 \%)$. An evaluation of several flavonoid assays showed that the estimation of the total flavonoid content in unknown samples was inaccurate and that various flavonoid types require different analytical techniques [32, 33]. Therefore, the results presented in Table 3 are considered as a relative comparison of the fractions.

Secondary metabolites like phenols, flavonoids, and saponins are known to contribute to the antioxidant activity of plants [34] and act as anti-inflammatory agents $[35,36]$. This led to the hypothesis that the phenolic content of fraction I may contribute mostly to the inhibition of COX-2, while the enriched amount of saponins in fraction III could be responsible for the significant inhibition of NF- $\kappa$ B. For a better understanding of the inhibition of NF- $\kappa \mathrm{B}$, the isolation of compounds from fraction III was targeted.

\subsection{Quantification and Structure Identification of Secondary} Metabolites. Main peaks (1-5) of fraction III were quantified via HPLC-CAD using a calibration curve with caffeine as internal standard (Figure 7(a)). A preparative separation of these peaks was performed via HPLC-PDA $(200 \mathrm{~nm})$ to isolate unknown compounds (Figure 7(b)). In addition, structure elucidation with HRMS and NMR was employed to analyze the obtained peaks and to draw conclusions about the anti-inflammatory (NF- $\kappa \mathrm{B})$ activities illustrated in Figure 6(b). All results are presented in Table 4.

According to the quantification via HPLC-CAD method, five main peaks correspond to $96.9 \%$ of fraction III. Peak 1 is a substantial part of this fraction with $45.2 \%$, while peaks $2-4$ equal between 11.3 and $19.2 \%$ and peak 5 corresponds to 


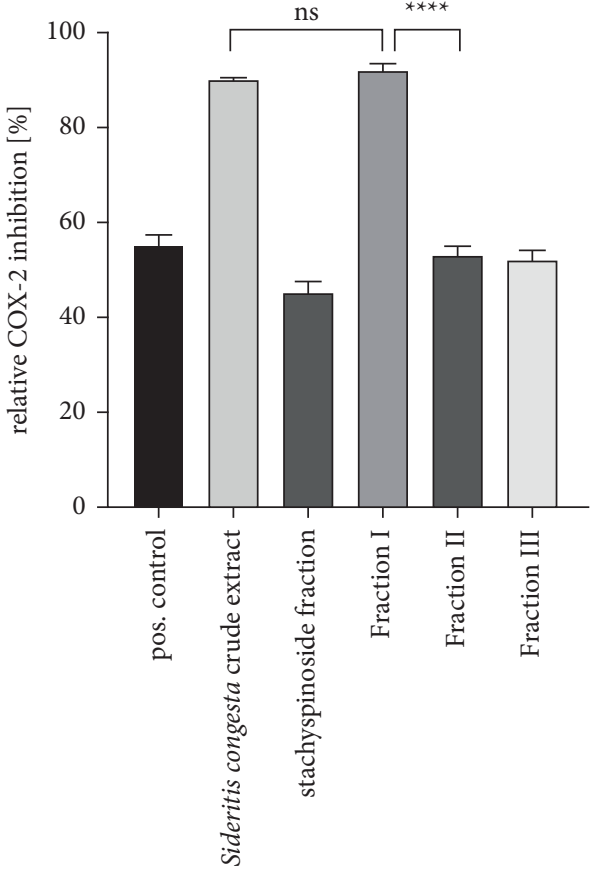

(a)

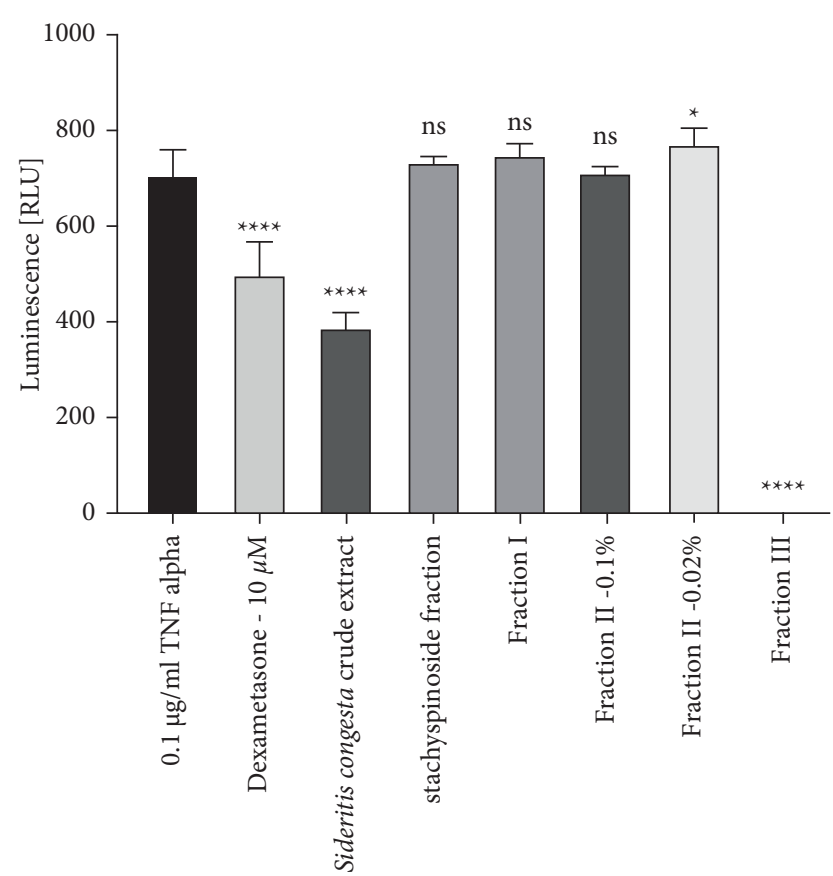

(b)

Figure 6: (a) Anti-inflammatory activity of $S$. congesta crude extract and fractions on COX-2 at a test concentration of $0.1 \%$. Results were expressed as mean \pm SD $(n=6) ;{ }^{* * * *} p<0.0001 \%$ vs. other CPC fractions; ns vs. fraction I. Statistical analysis was performed by one-way variance analyses (ANOVA) followed by Tukey's test for post hoc analysis. The relative inhibition of enzymatic COX-2 was calculated with equation (4) between $T_{2}=220$ seconds and $T_{1}=37$ seconds. Celecoxib $(0.5 \mu \mathrm{M})$ was used as a positive control. (b) Anti-inflammatory activity of $S$. congesta crude extract and fractions on NF- $\kappa \mathrm{B}$ at a test concentration of $0.1 \%$. Fraction II was further tested at $0.02 \%$ due to the results of the cytotoxicity assay. Results were expressed as mean $\pm \mathrm{SD}(n=6) ;{ }^{* * * *} p<0.0001 \%$ vs. control solution $(0.1 \mu \mathrm{g} / \mathrm{mL} \mathrm{TNF}$ alpha); ${ }^{*} p=0.0114 \%$ vs. control solution $(0.1 \mu \mathrm{g} / \mathrm{mL}$ TNF alpha); ns vs. TNF alpha control solution $(0.1 \mu \mathrm{g} / \mathrm{mL}$ TNF alpha). Statistical analysis was performed by one-way variance analyses (ANOVA) followed by Dunnett's post hoc analysis (test compound vs. TNF alpha control solution). The inhibition of cellular NF- $\kappa \mathrm{B}$ was calculated with equation (5). Dexamethasone (10 $\mu \mathrm{M})$ was used as positive control.

TABLE 3: Quantification of different secondary metabolite groups.

\begin{tabular}{lccc}
\hline \multirow{2}{*}{ Assays } & \multicolumn{3}{c}{ S. congesta extract samples } \\
& Crude extract $^{\text {Fraction III }}$ \\
\hline Total phenolic content $\left(\mathrm{mg} \mathrm{GAE} / \mathrm{g}\right.$ extract) $^{\mathrm{b}}$ & $145.0 \pm 0.20^{\mathrm{a}}$ & $102.3 \pm 0.15^{\mathrm{a}}$ & \\
Total saponin content $\left(\mathrm{mg} \mathrm{OAE} / \mathrm{g}\right.$ extract) $^{\mathrm{c}}$ & $55.5 \pm 0.87^{\mathrm{a}}$ & $39.6 \pm 1.78^{\mathrm{a}}$ & $46.4 \pm 0.08^{\mathrm{a}}$ \\
Total flavonoid content $\left(\mathrm{mg} \mathrm{SE} / \mathrm{g}\right.$ extract) $^{\mathrm{d}}$ & $158.2 \pm 1.07^{\mathrm{a}}$ & $108.5 \pm 0.19^{\mathrm{a}}$ & $251.7 \pm 0.95^{\mathrm{a}}$ \\
\hline
\end{tabular}

The results are determined within the software Prism $7 .{ }^{\mathrm{a}}$ Results were expressed as mean $\pm \operatorname{SD}(n=3) ;{ }^{* * * *} p<0.0001 \%$ vs. other fractions. ${ }^{\mathrm{b}} \mathrm{GAE}$ : gallic acid equivalent. ${ }^{\mathrm{c}} \mathrm{OE}$ : oleanolic acid equivalent. ${ }^{\mathrm{d}} \mathrm{SE}$ : stachyspinoside equivalent.

4.4\%. By comparing the HRMS and NMR spectra data, two peaks were unequivocally identified, namely, linearol 2 (peak 1) and epicandicandiol 3 (peak 5). Peak 2 shows a similar structure according to the NMR spectra and the same molecular formula according to the HRMS analysis as peak 1. An impurity by a second compound prevents an unambiguous structure elucidation of peak 2. Peaks 3 and 4 are mixtures that are not sufficiently separated for structural elucidation. Further experiments with an optimized chromatographic separation method are needed. The HRMS analysis data of peak 1 resulted in a different molecular formula than the NMR analysis. One possible explanation is the cleavage of the acetyl group from linearol 2 under the selected conditions. A repetition of the HRMS analysis resulted in a detected mass $[\mathrm{M}+\mathrm{H}]^{+}$of $363.25299(\mathrm{~m} / z)$, which correspond to the NMR results and confirmed the structure of the ent-kaurene diterpenoid linearol 2.

All identified secondary metabolites from fraction III belong to the group of ent-kaurane diterpenoids. These substances had been previously isolated from several Sideritis species including $S$. congesta $[9,37,38]$ with petroleum ether or acetone. Linearol $\mathbf{2}$ is one of the most common entkaurane diterpenoid found in Sideritis species [39] and is described among other diterpenoids as inhibitor of COX-2 and NF- $\kappa B[17,39,40]$. Fraction III is an enriched fraction of ent-kaurane diterpenoids, which explains the significant anti-inflammatory results in this study. The quantification of the total saponin content from fraction III resulted in a $251.7 \mathrm{mg} / \mathrm{g}$ extract. J.D. Few underlined that nonsteroids can be wrongly detected with this method [41], which could 


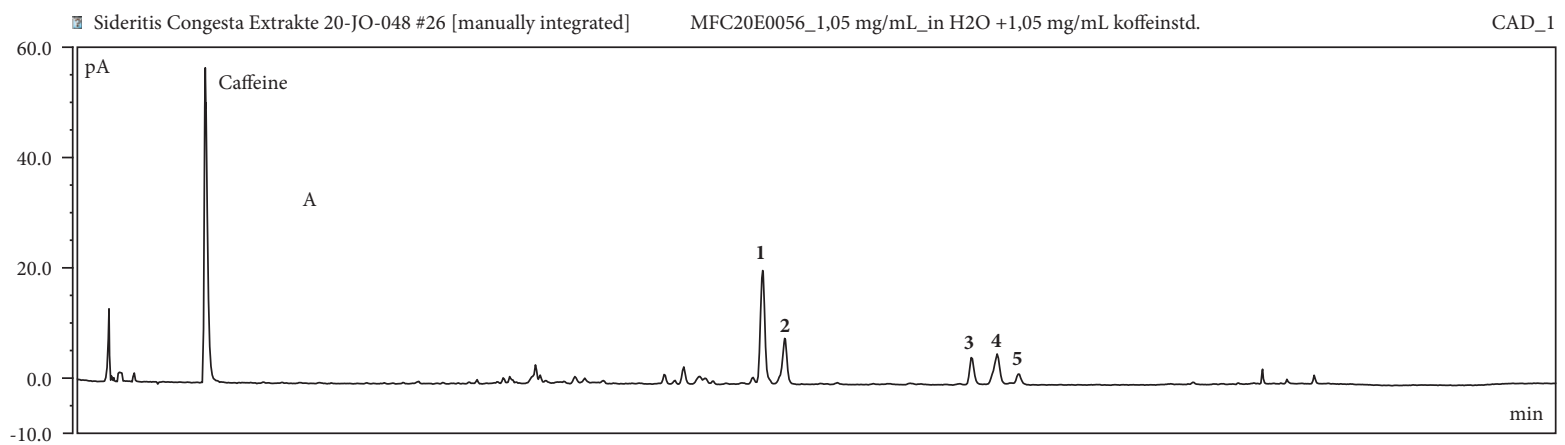

(a)

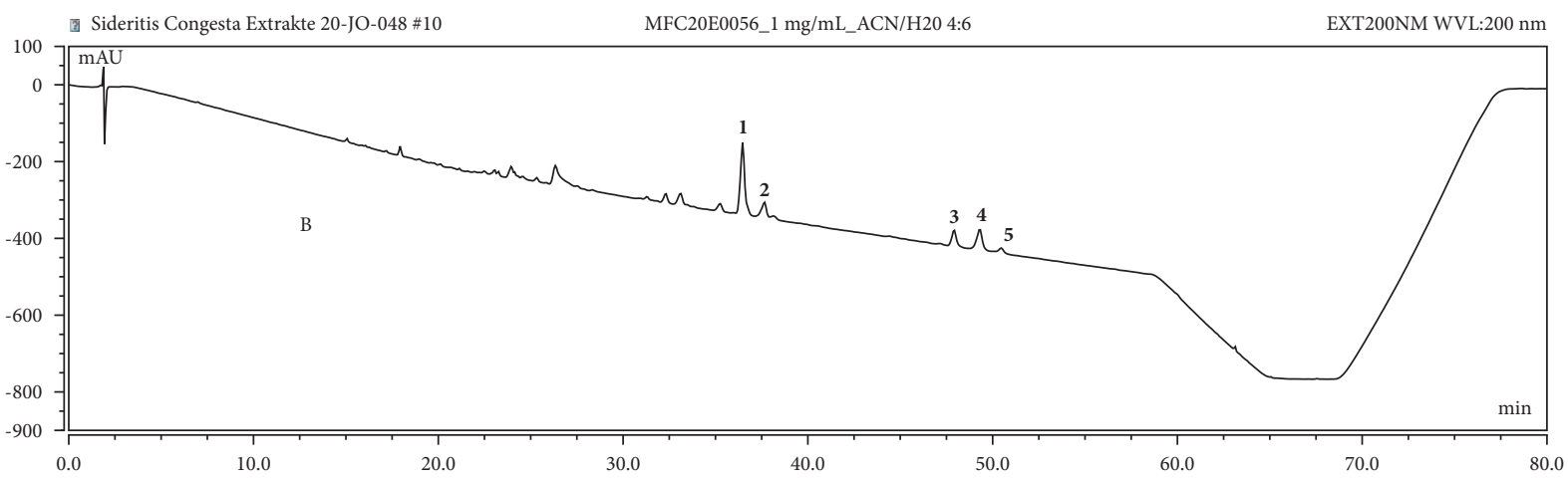

(b)

Figure 7: (a) An example HPLC-CAD chromatogram of fraction III used for the quantification of peaks 1-5 with caffeine as internal standard. (b) HPLC-PDA chromatogram of preparative separation of fraction III. The collection of the peaks 1-5 was performed with a fraction collector Foxy R1 (KNAUER) at $200 \mathrm{~nm}$. The obtained solutions were evaporated, and the dried residues were used for the structure identification via HRMS and NMR.

TABLE 4: Quantification of five main peaks in fraction III.

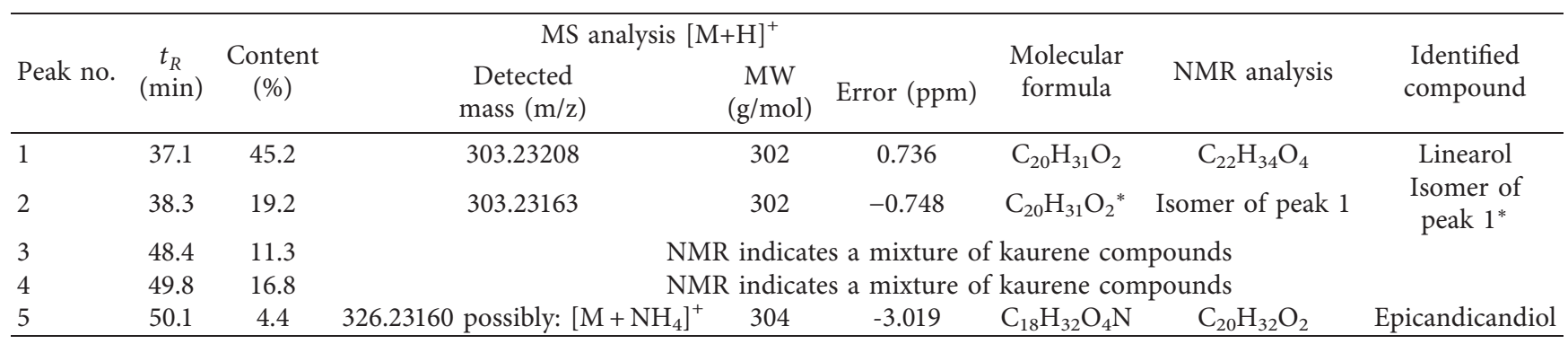

${ }^{*}$ Peak 2 showed a main compound in the HRMS analysis with the same observed molar weight as peak 1 . The structural identification was achieved with ${ }^{1} \mathrm{H}$ ,${ }^{13} \mathrm{C}-\mathrm{NMR}$, and HRMS (see Appendix).

explain the obtained results from the quantification of saponins and the results of the structure elucidation. Further experiments need to be performed with a linearol standard in the total saponin assay to validate this hypothesis.

\section{Conclusion}

In the present research, the anti-inflammatory potential of CPC fractions from an aqueous extract of $S$. congesta is assessed for their ability to inhibit COX-2 activity and NF- $\kappa \mathrm{B}$ transnucleation in vitro. CPC fractions I and III exhibited significant anti-inflammatory activities. The phenol, saponin, and flavonoid contents were quantified and compared in fractions I and III to better understand the anti-inflammatory results.

Phytochemical studies on fraction III led to the identification of two ent-kaurane diterpenoids, linearol 2, epicandicandiol 3 and probably of one isomer of linearol 2. Ent-kaurane diterpenoids are known anti-inflammatory agents. The isolated flavonoid stachyspinoside $\mathbf{1}$ (purity $>95 \%$ ) did not show an anti-inflammatory activity of the end points measured.

This article reports the first single-step CPC process for the isolation of stachyspinoside $\mathbf{1}$ from an aqueous $S$. congesta extract. The described CPC fractionation protocol was shown to be an effective method for the 
purification of bioactive natural compounds. The identification of potent anti-inflammatory agents in the aqueous extract of $S$. congesta provided a scientific rational for the traditional use of this plant.

$\propto$ : $\quad$ Separation factor

AA: Ammonium acetate

$\mathrm{ASE}^{\mathrm{TM}} \quad$ Accelerated solvent extraction device

350:

ATP: $\quad$ Adenosine triphosphate

CAD: $\quad$ Charged aerosol detector

ChMWat: Solvent system: chloroform/methanol/water

CCC: Countercurrent chromatography

COX-2: Cyclooxygenase-2 enzyme

CPC: Centrifugal partition chromatography

DAD: Diode array-detector

EbuWat: Solvent system: ethyl acetate/n-butanol/water

K: $\quad$ Partition coefficient

NF- $\kappa$ B: Nuclear factor kappa-light-chain-enhancer of activated B cells (protein)

Min: $\quad$ Minutes (time)

pA: $\quad$ Picoampere (unit of charged aerosol detector)

SST: $\quad$ Stainless steel

terAcWat: Solvent system: tert-butyl methyl ether/ acetonitrile/water

v/v: Volume/volume percentage.

\section{Data Availability}

All data supporting material are in the Supplementary Materials file.

\section{Conflicts of Interest}

All authors declare that they do not have any conflicts of interest regarding the publication of this paper.

\section{Acknowledgments}

The authors thank Julia Volk and Lisa Eckelhoefer for their contribution of all biological experiments. In addition, the authors are grateful for the important support in the structure elucidation from Dr. Martin Vogtherr's team (Merck's central analytical NMR department). This research was funded by Merck KGaA, Darmstadt, Germany.

\section{Supplementary Materials}

The authors provide additional instrumental analytical methods and data in the supplementary data section. The following figures and tables can be found in the supplementary data. Fig. S1. Structure of stachyspinoside 1. Fig. S2. Structure of linearol 2. Fig. S3. Structure of epicandicandiol 3. Fig. S4. UV-chromatogram of stachyspinoside $\mathbf{1}$ fraction. Fig. S5. TIC-MS of stachyspinoside 1 fraction. Fig. S6. Mass spectrum and fragmentation of stachyspinoside 1. Table S1. HPLC conditions for the characterization of S. congesta crude extract. Table S2. HPLC conditions of secondary metabolites from S. congesta. Table S3. HPLC conditions for the characterization of CPC fraction III. Table S4. HPLC conditions for the characterization of secondary metabolites from S. congesta. . (Supplementary Materials)

\section{References}

[1] C. N. Obón de Castro and D. Rivera Nuñez, A Taxonomic Revision of the Section Sideritis (Genus Sideritis) (Labiatae), J. Cramer, Berlin, Germany, 1994.

[2] H. Fakir, M. Korkmaz, and B. Icel, "Medicinal plant diversity of western mediterranean region in Turkey," Journal of Applied Biological Sciences, vol. 3, pp. 30-40, 2009.

[3] C. N. Gabrieli, P. G. Kefalas, and E. L. Kokkalou, "Antioxidant activity of flavonoids from Sideritis raeseri," Journal of Ethnopharmacology, vol. 96, no. 3, pp. 423-428, 2005.

[4] A. Pieroni, H. Muenz, M. Akbulut, K. H. C. Başer, and C. Durmuşkahya, "Traditional phytotherapy and trans-cultural pharmacy among Turkish migrants living in Cologne, Germany," Journal of Ethnopharmacology, vol. 102, no. 1, pp. 69-88, 2005.

[5] A. Everest and E. Ozturk, "Focusing on the ethnobotanical uses of plants in Mersin and Adana provinces (Turkey)," Journal of Ethnobiology and Ethnomedicine, vol. 1, no. 1, p. 6, 2005.

[6] N. Erkan, H. Cetin, and E. Ayranci, "Antioxidant activities of Sideritis congesta Davis et Huber-Morath and Sideritis arguta Boiss et Heldr: identification of free flavonoids and cinnamic acid derivatives," Food Research International, vol. 44, no. 1, pp. 297-303, 2011.

[7] A. Gökbulut, A. Yazgan, H. Duman, and B. Yilmaz, "Evaluation of the antioxidant potential and chlorogenic acid contents of three endemic sideritis taxa from Turkey," Fabad Journal of Pharmaceutical Sciences, vol. 42, pp. 81-86, 2017.

[8] E. González-Burgos, M. E. Carretero, and M. P. GómezSerranillos, "Sideritis spp.: uses, chemical composition and pharmacological activities-a review," Journal of Ethnopharmacology, vol. 135, pp. 209-225, 2011.

[9] G. Topçu, A. Ertaş, M. Öztürk, D. Dinçel, T. Kılıç, and B. Halfon, "Ent-kaurane diterpenoids isolated from Sideritis congesta," Phytochemistry Letters, vol. 4, pp. 436-439, 2011.

[10] Y. Akcos, N. Ezer, I. Çalis, R. Demirdamar, and B. C. Tel, "Polyphenolic compounds of sideritis lycia and their antiinflammatory activity," Pharmaceutical Biology, vol. 37, no. 2, pp. 118-122, 1999.

[11] I. Erdogan-Orhan, E. Baki, S. Şenol, and G. Yilmaz, "Sagecalled plant species sold in Turkey and their antioxidant activities," Journal of the Serbian Chemical Society, vol. 75, no. 11, pp. 1491-1501, 2010.

[12] E. Yeşlada and N. Ezer, "The antiinflammatory activity of some sideritis species growing in Turkey," Pharmaceutical Biology, vol. 27, pp. 38-40, 2008.

[13] E. Loğoğlu and A. öktemer, "Isolation of a new diterpene from sideritis congesta," Communications, Faculty Of Science, University of Ankara Series B Chemistry and Chemical Engineering, vol. 49, pp. 1-3, 2003.

[14] E. E. Sezik, "Nurten Phytochemical investigations on the plants used as folk medicine and herbal tea in Turkey. I. Flavonoids of Sideritis congesta Davis et Huber-Morath," Acta Pharmaceutica Turcica, vol. 26, pp. 4-10, 1984.

[15] A. Gümüşçü, O. Tugay, and Y. Kan, "Comparison of essential oil compositions of some natural and cultivated endemic sideritis species," Advances in Environmental Biology, vol. 5, pp. 222-226, 2011.

[16] M. Z. Özel, A. C. Lewis, and F. Gögüs, “Chemical composition of volatile oils from leaves and flowers of sideritis congesta 
using direct thermal desorption - two - dimensional gas chromatography - time - of - flight mass spectrometry," Journal of Essential Oil Bearing Plants, vol. 11, pp. 22-29, 2008.

[17] E. González-Burgos, M. E. Carretero, and M. P. GómezSerranillos, "Involvement of Nrf2 signaling pathway in the neuroprotective activity of natural kaurane diterpenes," Neuroscience, vol. 231, pp. 400-412, 2013.

[18] A. Berthod, T. Maryutina, B. Spivakov, O. Shpigun, and I. A. Sutherland, "Countercurrent chromatography in analytical chemistry (IUPAC Technical Report)," Pure and Applied Chemistry, vol. 81, no. 2, pp. 355-387, 2009.

[19] A. Berthod and S. Carda-Broch, "Determination of liquidliquid partition coefficients by separation methods," Journal of Chromatography A, vol. 1037, no. 1-2, pp. 3-14, 2004.

[20] J.-S. Jeon, C. L. Park, A. S. Syed, Y.-M. Kim, I. J. Cho, and C. Y. Kim, "Preparative separation of sesamin and sesamolin from defatted sesame meal via centrifugal partition chromatography with consecutive sample injection," Journal of Chromatography B, vol. 1011, pp. 108-113, 2016.

[21] M.-C. Menet and D. Thiebaut, "Preparative purification of antibiotics for comparing hydrostatic and hydrodynamic mode counter-current chromatography and preparative highperformance liquid chromatography," Journal of Chromatography A, vol. 831, no. 2, pp. 203-216, 1999.

[22] K. Hostettmann and A. Marston, "Liquid-liquid partition chromatography in natural product isolation," Analytica Chimica Acta, vol. 236, pp. 63-76, 1990.

[23] E. Bouju, A. Berthod, and K. Faure, "Carnosol purification. Scaling-up centrifugal partition chromatography separations," Journal of Chromatography A, vol. 1466, pp. 59-66, 2016.

[24] Y. Ito, "Golden rules and pitfalls in selecting optimum conditions for high-speed counter-current chromatography," Journal of Chromatography A, vol. 1065, no. 2, pp. 145-168, 2005.

[25] D. Satyajit and L. N. Sarker, Natural Products Isolation Methods and Protocols, Springer Science + Business Media, Berlin, Germany, Third edition, 2012.

[26] V. L. Singleton and J. A. Rossi, "Colorimetry of total phenolics with phosphomolybdic-phosphotungstic acid reagents," American Journal of Enology and Viticulture, vol. 16, p. 144, 1965.

[27] T. Oludemi, L. Barros, M. A. Prieto, S. A. Heleno, M. F. Barreiro, and I. C. F. R. Ferreira, "Extraction of triterpenoids and phenolic compounds from Ganoderma lucidum: optimization study using the response surface methodology," Food \& Function, vol. 9, no. 1, pp. 209-226, 2018.

[28] C. C. Chang, M. H. Yang, H. M. Wen, and J. C. Chern, "Estimation of total flavonoid content in propolis by two complementary colorimetric methods," Journal of Food and Drug Analysis, vol. 10, pp. 178-182, 2002.

[29] H. Bardakci, D. Cevik, T. H. Barak, T. Gozet, Y. Kan, and H. Kirmizibekmez, "Secondary metabolites, phytochemical characterization and antioxidant activities of different extracts of Sideritis congesta P.H. Davis et Hub.-Mor," Biochemical Systematics and Ecology, vol. 92, Article ID 104120, 2020.

[30] L. A. L. Da Silva, L. P. Sandjo, E. Fratoni, Y. J. Kinoshita Moon, E. M. Dalmarco, and M. W. Biavatti, "A single-step isolation by centrifugal partition chromatography of the potential anti-inflammatory glaucolide B from Lepidaploa chamissonis," Journal of Chromatography A, vol. 1605, Article ID 460362, 2019.
[31] K. Skalicka-Wozniak and I. Garrard, "Counter-current chromatography for the separation of terpenoids: a comprehensive review with respect to the solvent systems employed," Phytochemistry Reviews, vol. 13, pp. 547-572, 2014.

[32] Y.-C. Ho, H.-T. Yu, and N.-W. Su, "Re-examination of chromogenic quantitative assays for determining flavonoid content," Journal of Agricultural and Food Chemistry, vol. 60, no. 10, pp. 2674-2681, 2012.

[33] D. Mammen and M. Daniel, "A critical evaluation on the reliability of two aluminum chloride chelation methods for quantification of flavonoids," Food Chemistry, vol. 135, no. 3, pp. 1365-1368, 2012.

[34] L. Zhang, A. S. Ravipati, S. R. Koyyalamudi et al., "Antioxidant and anti-inflammatory activities of selected medicinal plants containing phenolic and flavonoid compounds," Journal of Agricultural and Food Chemistry, vol. 59, no. 23, pp. 12361-12367, 2011.

[35] R. Hendra, S. Ahmad, E. Oskoueian, A. Sukari, and M. Y. Shukor, "Antioxidant, anti-inflammatory and cytotoxicity of phaleria macrocarpa (boerl.) scheff fruit," $B M C$ Complementary and Alternative Medicine, vol. 11, no. 1, p. 110, 2011.

[36] X.-D. Su, H.-J. Jang, C.-Y. Wang et al., “Anti-inflammatory potential of saponins from aster tataricus via NF- $\kappa \mathrm{B} / \mathrm{MAPK}$ activation," Journal of Natural Products, vol. 82, no. 5, pp. 1139-1148, 2019.

[37] T. Kilic, G. Topcu, A. C. Goren et al., "Ent-kaurene diterpenoids from sideritis lycia with antiviral and cytotoxic activities," Records of Natural Products, vol. 14, 2020.

[38] S. Çarıkçı, T. Kılıç, A. Azizoglu, and G. Topcu, "Chemical constituents of two endemic sideritis species from Turkey with antioxidant activity," Records of Natural Products, vol. 6, 2012.

[39] E. González-Burgos, A. I. Duarte, M. E. Carretero, P. I. Moreira, and M. P. Gómez-Serranillos, "Kaurane diterpenes as mitochondrial alterations preventive agents under experimental oxidative stress conditions," Pharmacien Biologiste, vol. 54, pp. 705-711, 2016.

[40] B. de las Heras, S. Hortelano, N. Girón, P. Bermejo, B. Rodríguez, and L. Boscá, "Kaurane diterpenes protect against apoptosis and inhibition of phagocytosis in activated macrophages," British Journal of Pharmacology, vol. 152, no. 2, pp. 249-255, 2007.

[41] J. D. Few, "Some new steroid colour reactions," The Analyst, vol. 90, no. 1068, pp. 134-146, 1965. 